\title{
O Imaginarium Diegético na Animação e no Cinema: a representação de momentos de sonho, memória, devaneio e psicadelia no Audiovisual
}

\author{
Eliane Gordeeff
}

FBAUL-CIEBA, Portugal / UVA e CNPq, Brasil

João Paulo Queiroz

FBAUL-CIEBA, Portugal

\begin{abstract}
This article has the purpose of discussing about the representation of dreams, memory, reverie or psychedelic moments of the character - diegetic imaginarium - by the Audiovisual (Live-action Cinema and Animation) for the development and understanding of film analysis. With this objective the adopted borders to the imaginarium (the caracter mental image) are approached; its role in the construction of narratives, its representations, and how it favors the abstraction and deepening of the public in the stories. Thus, it is developed a particular looking over the animated image, when it is responsible for the representation of the illusional image, while the filmed one represents the reality of the same diegese. The paper is based on studies about mental image in relation to Animation (Sifianos, 2012), the perception of the cinematographic image (Metz, 1975a, 1994; Morin, 1956) and of the mental image (Arnheim, 1971, 2004). The subject is also developed with evaluations and considerations on some Psychology concepts, about mental images and their representations by the audiovisual. This text was developed during the doctoral research, The Representation of the Diegetic Imaginarium for Animation, in the Cinema Live-action, presented at the Faculty of Fine Arts of the University of Lisbon in 2018.
\end{abstract}

Keywords: Diegetic Imaginarium, Animated Image, Live-Action Image, Mental Image, Animated Representation

\section{O Imaginário e o Cinema}

A ligação entre a imagem do Cinema e o imaginário, sempre despertou interesse desde o início da sétima arte. Textos como, Le Mécanisme Cinématographique de la Pensée (Bergson 2008) ou Les Vues Cinématographiques (Méliès 2008) observam as semelhanças entre a imagem vista no ecrã e as criadas mentalmente pelo homem.

Edgar Morin $(1956,83)$ afirma que 'L'imaginaire est la pratique magique spontanée de l'esprit qui rêve" $(1956,83)$ e que é "le lieu commun de l'image et de l'imagination" (1956, 84).

Nous entrons dans le royaume de l'imaginaire quand les aspirations, les désirs, et leurs négatifs, les craintes et les terreurs, emportent et modèlent l'image pour ordonner selon leur logique les rêves, mythes, religions, croyances, littératures, précisément toutes les fictions (83).
O advento da Animação e do Cinema abriram o caminho para a supremacia da ficção, e da "ilusão" sem precedentes. Através da obra de Georges Méliès, Morin explica essa teatralidade "espetacular": "[...] des machines, et l'irréalité de Méliés se déploie aussi flagrante que le fut la réalité des frères Lumière" (1956, 58). Com a ficção, tudo tornou-se possível. Méliès não fazia distinção entre o que era "real" ou "irreal". Mesclando técnicas do teatro e de prestidigitação, criou as bases dos efeitos especiais para o Cinema, utilizando entre outros artifícios, a técnica de stop-action (Harryhausen e Dalton 2008, 38) - nome então utilizado para o Stop motion.

Christian Metz, analisando a relação da imagem cinematográfica com o imaginário humano, observa

Davantage que les autres arts, ou de façon plus singulière, le cinéma nous engage dans l'imaginaire: il fait lever en masse la perception, mais pour la basculer aussitôt dans sa propre absence, qui est néanmoins le seul signifiant présent (1975a, 32).

Não há uma presença real no Cinema, que é constituído de representantes e significantes, imaginários. E destaca-se que a verosimilhança ${ }^{1}$, impressão de realidade ${ }^{2}$ e suspensão da descrença ${ }^{3}$ também agem sobre o espetador, reforçando a ilusão.

Morin $(1956,157)$ também observa as similaridades entre o cinema e o sonho:

les structures du film [...] répondent aux mêmes besoins imaginaires que celles du rêve; la séance de cinéma révèle des caractères para-hypnotiques (obscurité, envoûtement par l'image, relaxation 'confortable', passivité et impuissance physique).

E se a ficção é uma ilusão, a abstração (do público) dos referenciais de realidade, reforça esse estado.

Les actualités perdent elles-mêmes leur réalité pratique : les actes réels originaux sont passés, absents; le spectateur sait qu'il voit une image, et dé-réifie sa vision pour la ressentir esthétiquement. Aussi, par rapport au rêve ou à l'hallucination [...] le cinéma est un complexe de réalité et d 'irréalité ; il détermine un état mixte, [...] (Morin 1956, 157).

Como é possível perceber, a relação entre cinema e as imagens mentais há muito são tema de estudo, sob diversos pontos de vista. Porém, apesar da atual imagem híbrida do Cinema - imagem filmada + animação + efeitos digitais -, muito ainda carece de estudo e análise, ao se tratar de Animação. Alan 
Cholodenko (1991) entre outros (Baecque, Chevallier 2016; Wells 2002) abordam essa necessidade, pois a Animação sempre foi considerada uma parte "técnica" do Cinema - como os "efeitos especiais".

A imagem animada tem atraído a atenção do Film Studies (Cholodenko 2007) somente nos últimos anos, provavelmente devido a sua maior apropriação (mais definitiva e estrutural) pelas produções live-action. $\mathrm{O}$ que é uma preocupação importante, mas tardia, uma vez que tal composição existe desde 1909, registada nos filmes de Émile Cohl (1857-1938) 4 .

Portanto, este artigo aborda esse assunto através do estudo da Animação na representação ${ }^{5}$ de momentos de sonho ${ }^{6}$, devaneio ${ }^{7}$, lembrança ${ }^{8}$ ou psicadelia ${ }^{9}$ do personagem - o imaginarium ${ }^{10}$ diegético - nas narrativas em Live-action. Disserta-se sobre as fronteiras adotadas sobre o imaginarium (imagem mental); o seu papel na construção das narrativas, e como as suas representações favorecem à abstração e ao aprofundamento do público.

Por essa vertente, desenvolve-se uma atenção sobre a imagem animada, como representação da imagem mental da diegese, enquanto a filmada representa a realidade desta. Para tanto, são observados trabalhos que abordam a imagem mental em relação a Animação (Sifianos 2012), a perceção da imagem cinematográfica (Metz 1975a, 1994; Morin 1956), e da imagem mental (Arnheim 1971, 2004). Além de considerações sobre alguns estudos da Psicologia, e das representações desses estados pelo audiovisual.

Destaca-se que este texto foi desenvolvido durante a investigação doutoral, A Representação do Imaginarium Diegético pela Animação, no Cinema Live-action, apresentada na Faculdade de Belas-Artes da Universidade de Lisboa, em 2018.

\section{A Imagem Mental}

Tudo é imagem. A relação do homem com o mundo se dá, principalmente, através do sentido da visão e da identificação do que se vê. A história de cada indivíduo, os pensamentos e memórias do passado são imagens vistas, criadas e guardadas na mente de cada um. Neste sentido, em termos de corpo, não há diferenças entre elas: as imagens de uma lembrança, de um sonho ou do pensamento, são mentais. Segundo o psicólogo Dr. Daniel Schacter (Je Me Souviens Donc Je Me Trompe 2016), da Universidade de Harvard, o ato de lembrar e imaginar ativam as mesmas áreas cerebrais (a do hipotálamo), e não há como assegurar que uma cena guardada na memória é "verdadeira", pois ela é modificável - "is not a video record, but a Wikipedia page, which can be accessed and edited", como explica a Dra. Elizabeth Loftus, da Universidade da Califórnia (Je Me Souviens Donc Je Me Trompe 2016). É como um material maleável, que sofre interferências de impressões e informações diversas. O que explica a confusão entre as lembranças de ações ou registos quotidianos, como por exemplo, quando se acha que a porta de casa foi trancada, mas na verdade não o foi.
Portanto, considera-se imagem mental, qualquer imagem criada consciente (ou inconscientemente), ou armazenada pela mente humana na memória.

Segundo Arnheim,

Thinking, in particular, can deal with objects and events only if they are available to the mind in some fashion. In direct perception, they can be seen, sometimes even handled. Otherwise they are represented indirectly by what is remembered and known about them. $(1971,98)$

"But memory can take things out of their contexts and show them in isolation" (Arnheim 1971, 104), e há um

"[...] sort of incompleteness is typical of mental imagery. It is the product of the selectively discerning mind, which can do better than consider faithful recording of fragments" (p. 105).

\section{Para Jacques Aumont $(2001,118)$,}

É 'imagem mental' aquilo que, em nossos processos mentais, não pode ser imitado por um computador que utiliza informação binária. A imagem mental não é, portanto, uma espécie de 'fotografia' interior da realidade, mas uma representação 'codificada 'da realidade $[\ldots]$.

Ou seja, a criação mental das imagens ocorre, quando estas são resultado da visão, de uma imagem ou de um momento vivido.

George Sifianos também faz algumas observações que corroboram com Arnheim e Aumont: "Les images mentales ne sont donc pas des images naturalistes. Elles sont abstraites" $(2012,56)$. E têm a tendência a "guardar" o todo, não o detalhe. A Gestalt inclusive assim explica como se processa a perceção humana: "Any stimulus pattern tends to be seen in such a way that the resulting structure is as simple as the given conditions permit" (Arnheim 2004, 53). Arnheim destaca que

\begin{abstract}
If we wish to make pictures on a plane surface, all we can hope to do is to produce a translation that is, to present some structural essentials of the visual concept by two-dimensional means. The pictures achieved in this way may look flat like a child's drawing or have depth like those obtained with a stereoscope or holograph, but in both the problem remains that the all roundness of the visual conception cannot be reproduced directly in a single plane. $(2004,107)$
\end{abstract}

O que explica que a simplificação da visualização das formas, diferencia a imagem mental da obtida pela perceção visual.

"L'image mentale se satisfait de la reconnaissance de son objet" (Sifianos 2012, 57), uma vez que, ao ver uma imagem previamente registada na memória, logo se cria uma identificação e revive-se aquela recordação (se houver). O reconhecimento do que é visto é "the most useful and common interaction between perception and memory", porém a 
"Recognition presupposes the presence of something to be recognized" (Arnheim 1971, 90). Aumont também considera o reconhecimento como um dos principais investimentos psicológicos da imagem (2011, 83). Por consequência, há uma tentativa em lembrar dos detalhes daquele momento. É a tendência '"vers' la 'complétude'” (Sifianos 2012, 57) (da imagem), que quase sempre fracassa, pois "les images mentales se situent entre mémoire et oubli. [...]. [...] qui réduit les images à leur structure de base" (p. 58). Essa imagem de natureza abstrata é incompleta, sendo "plus apte à être possédée qu'à posséder" (Sifianos 2012, 65). Confirmando que esta é suscetível à manipulação, pois é instável, podendo ser modificada $(2012,65)$. Arnheim $(1971,104)$ ainda reforça que a mente "can cut pieces from the cloth of memory, [...], can also make collages from memory material, by imagining centaurs or griffins".

Sifianos $(2012,69-70)$ destaca as diferenças entre a imagem mental e a fotográfica (o que pode ser aplicado à imagem filmada):

Le cinéma - en tant qu'image filmée de la nature n'est pas la réalité objective. C'est la réalité traduite par le matériel technique dans une « réalité » de deuxième génération. Respectivement, l'image peinte ${ }^{11}$ - qui est filmée et projetée - n'est pas l'image mentale, mais une image mentale secondaire. Dans le cas d'image projetée à l'écran, la réalité secondaire coïncide avec l'image mentale seconde. L'image photographique d'un objet correspond, en principe, plus á la réalité de l'objet qu'à son équivalent que nous formons en tant qu'image mentale. [...] Dans la peinture donc, le processus va de l'image mentale à l'image peinte. Par contre dans la photographie il va de la réalité á la photographie, sans l'intervention du processus mental. Par conséquent, l'image photographique tend à être considérée comme réalité objective, tandis que l'image peinte est considérée comme subjective, non réelle, création de l'imagination.

A afirmação explica a proximidade entre a imagem mental e as Artes Visuais, ao mesmo tempo que concorda com Barthes (1980, 16-18): a fotografia adere ao referente (ao real).

\section{Características Visuais e Auditivas dos Registos Mentais}

Com o objetivo de clarificar, é apresentado um breve panorama de sentido comum ${ }^{12}$, sobre como se processam as imagens criadas pela mente. $O$ que é importante pois é a identificação "comum" das similaridades com as imagens dos filmes, que colabora com a identificação desses momentos cinematográficos como sendo de sonho, lembrança, pensamento ou alucinação.

O pensamento é um fluxo sucessivo de imagens, que se alteram de acordo com o que se pensa, dinamicamente e nem sempre de forma lógica ou voluntária. Por exemplo, ao rememorar algum evento, espontaneamente, ao final de dois, três minutos termina-se por pensar sobre o que fazer no dia seguinte. Ou seja, pode-se terminar pensando em outra coisa (elaborada ou imaginada). É um pouco diferente quando se resolve um problema, pois há a atenção objetiva sobre a questão.

Os sons "produzidos" mentalmente, também são reproduções de memória, como acontece com as imagens. Logicamente é possível criar imagens novas, elaborar outras formas, imaginar sobre o futuro. Mas é um processo que acontece a partir de registos mentais (Gleitman, Fridlund e Reisberg 2014, 399), como já mencionado também por Arnheim. O que acontece são elaborações, através da criatividade, que temporariamente cria imagens. Se não escrevermos ou desenharmos, raramente é possível guardar na memória esses pensamentos com detalhes ${ }^{13}$.

Quando se sonha, geralmente as imagens parecem desfocadas, esfumaçadas e sem nitidez. As cores, às vezes, são pontuais ou inexistentes. Mas há sonhos "reais": coloridos, com odores, sensação de tato e emoção. Porém, na sua maioria, não há "lógica" no que acontece. As imagens se dissolvem, se sobrepõem ou se metamorfoseiam - como os efeitos de transição cinematográficos.

Todavia, quando se passa por alguma situação de alucinação - por ingestão de alguma substância, ou estado Psico-patológico que provoque tal efeito (esquizofrenia, por exemplo) - as imagens "vistas" podem ser semelhantes às dos sonhos. Ou muito realista, onde se pode ver e conversar com alguém, como se realmente existisse. Tais imagens não são resultado de um estado consciente da mente, mas de distúrbios fora do controle do indivíduo - como os sonhos se processam como uma manifestação do inconsciente (Freud 2012).

Essas distorções também ocorrem com os sons. O que se ouve nesses estados, também pode ser profundamente "real", ou sem nenhuma coerência com a imagem que se acredita ver - como "vozes do além". Tal reunião cria a sensação de insegurança, de desconhecido, de impotência diante de algo que não se tem controle - algo semelhante à sensação de se estar assistindo a um filme em uma sala escura.

\section{Semelhanças e Diferenças Visuais Entre as Imagens Mentais}

A partir deste ponto, é possivel identificar e caracterizar algumas semelhanças e diferenças subtis entre as imagens do imaginarium, considerando a sucessão de imagens e a impressão de passagem de tempo que estas carregam.

Enquanto o pensamento é inconstante variando de foco de forma direta, durante o sonho as imagens parecem se transformar uma na outra. O controle consciente do sonho é raro. A sensação da passagem de tempo, durante esses estados ou quando se está a "sonhar" acordado, também é algo incerto.

Como citado anteriormente, as imagens mentais são mais abstratas. Portanto, a passagem direta de uma imagem mental para outra, parece que ocorre em um rápido fade - fazendo uma analogia às transições cinematográficas - e não um corte, como um piscar de olhos - uma mudança imediata para outra imagem.

Contudo, a lembrança de um sonho, sempre se 
mostra mais "apagada" ainda, mais incerta que a de uma recordação de algo vivido (principalmente quando esta lembrança está ligada à uma emoção). As lembranças do casamento são mais nítidas, que as do noticiário, pois são carregadas de emoção (Gleitman, Fridlund e Reisberg 2014, 376). Tal facto é resultado da atenção dispensada e do envolvimento emocional. É a aplicação da expressão coloquial: "lembrei como se fosse um filme". Esta é consequência da identificação, pelo sentido comum, da semelhança das lembranças com a imagem filmada e a sua riqueza de detalhes. É a semelhança das lembranças vividas, como uma imagem real - novamente, o vínculo com a imagem fotográfica observada por Barthes e Sifianos. O que difere da pouca "completude" (termo de Sifianos) da imagem de um sonho ou pensamento.

Já a imagem de uma alucinação, pode ser bem mais inconstante, às vezes metamorfa e com ritmo acelerado ou lento, e sem a mínima lógica (como um sonho). Nesses estados, a noção de tempo é distorcida, dificultada pela completa ou parcial falta de consciência. Porém, no caso de uma alucinação ser detalhada e elaborada, como consequência de uma esquizofrenia, a noção de tempo é proporcional à realidade criada pela pessoa. $\mathrm{O}$ que pode ser completamente diferente do tempo cronológico. O filme A Beautiful Mind (Howard 2001), apresenta bem a história verídica do matemático John Nash (1928-2015), esquizofrénico, que quase enlouqueceu em um mundo próprio, com perseguições e amigos inexistentes.

\section{O Cinema e o Imaginarium (Imaginário)}

É possível imaginar qualquer ação ou acontecimento relacionando-o a qualquer situação. Não há limites para a imaginação humana. Mas para transformar estas imagens mentais em imagens visíveis é preciso criá-las fora da mente. Esse foi o nicho preenchido pela criação das imagens em movimento, o que antes só era possível através da Literatura, das Artes Plásticas e do Teatro.

Porém a primeira não fornece uma "imagem" exata, mas indicações e descrições que são usadas pelo leitor para criar a sua própria imagem mental da narrativa (através da imaginação). O filme apresenta as imagens dessa história. Como observa Metz, "le liseur du roman ne retrouve pas toujours son film, car ce qu'il a devant lui, avec le film véritable, c'est à présent le fantasme d'autrui [...]" (1975b, 115).

As Artes Plásticas apresentam uma imagem estática, como um instantâneo do pensamento - que não é estático -, bi ou tridimensional, mais ou menos semelhante a imagem mental, de acordo com a mestria e intenção do artista. Já o Teatro apresenta a ação, com movimentos e sons, no mesmo plano do espetador que assiste à encenação, à priori, sempre com o mesmo ponto de vista a partir da plateia.

Mas o que se vê no cinema é a projeção de imagens, de atores ausentes (desenhos ou objetos, no caso da animação), que foram filmados ou capturados, em locais (cenários) diferenciados.
O desenvolvimento da Animação e do Cinema Live-action possibilitou a criação de mundos e ações completamente dissociadas dos limites das possibilidades da realidade material. Como explica Gilbert Durand (1995, 10), “a imaginação simbólica é dinamicamente negação vital, negação do nada da morte e do tempo". Esses meios ofereceram à imaginação humana uma forma de extrapolar os limites do cérebro e de se apresentar, ela mesma, aos outros. É sentido comum também que através da Arte, o artista se imortaliza - e especialmente no caso dos atores do Cinema.

Mas existem diferenças. Enquanto no live-action há uma ligação inegável com o que se identifica como sendo real - a sua indissociável conexão com a Fotografia, e desta com o real -, em uma produção animada há uma dissociação visual da realidade (na grande maioria das vezes). As suas imagens podem se originar de uma folha de papel ou de uma caixa de areia, tendo como resultado imagens que simulam o movimento - que de facto, não existe. Essa diferença encontra paralelo nas duas maneiras de representar o mundo apontadas por Durand (1995, 7): Uma direta, na qual a própria coisa parece estar presente no espírito, como perceção ou uma simples sensação. A outra indireta quando, por esta ou aquela razão, a coisa não pode apresentar-se "em carne e osso" à sensibilidade. Como na recordação da nossa infância ou na compreensão da dança do eletrão em torno do núcleo atómico.

Essa é uma das possibilidades da Animação: a de transmutar as ações imaginadas em imagens visíveis, criando mundos que nunca foram vistos, simulando visualmente ações impossíveis e irreais a partir de coisas inanimadas ("sem alma"). Nas atuais produções de Live-action, a utilização da Animação e a criação de ambientes em 3D possibilitam a produção de cenários futuristas, históricos e irreais.

Porém as imagens, segundo Aumont $(2011,58)$, são resultado da imaginação, "faculté créative, productrice d'images intérieures éventuallement extériorisables". O imaginário, por definição de Metz:

combine en lui une certaine présence et une certaine absence. Au cinéma, ce n'est pas seulement le signifié fîctionnel, s'il y en a un, qui se rend ainsi présent sur le mode de l'absence, c'est d'abord le signifiant. (1975a, 31-32).

Portanto, o Cinema também funciona como um espelho, onde é possível a identificação do espetador com uma personagem, com uma situação ou com um lugar. O que se projeta no ecrã é uma imagem (de algo/ alguém ausente) que foi capturada por uma câmara. Porém, quem a assiste se identifica, ou a interpreta de acordo com seu conhecimento e experiências prévias - como explica Bergson (1999). A perceção sobre o que se apresenta não é total e completa, pois é sempre impregnada pelas informações existentes no repertório (memória) do indivíduo. Mas tal identificação do espetador também acontece com produções animadas, como no caso de Toy Story 3 (Unkrich 2010), onde o público se reconhece no momento em 
que a personagem abandona os brinquedos e entra na vida adulta. Ou seja, a identificação corporal é importante - como a repulsa, a inquietação natural que surge (Pavis 1996, 221) ao se visionar um cadáver -, mas esta não é mais importante que identificação da ação do que se vê e da emoção que desperta. O que é possível também com uma cena violenta, mesmo através de conotação ${ }^{14}$.

O processo de participação bem analisado por Metz (1994,14-15), é justificado pela impressão de realidade apresentada pelos filmes. Porém, essa impressão não se processa apenas ao se visionar, por exemplo, uma cena de batalha, como também quando se assiste ao sonho da personagem. Ou seja, entende-se e identifica-se com o que é visionado, pois o que se vê é semelhante às imagens de lembranças dos próprios sonhos. Além da posição da câmara com o ponto de vista da personagem, onde o sonho é muitas vezes, visto pelo espetador como sendo seu.

\section{O Tempo e a Metamorfose}

O tempo cronológico e a passagem do tempo são elementos importantes nas produções para o Cinema. A visão da sucessão de imagens estáticas em um determinado tempo, cria a ilusão do movimento. Mas além da questão técnica, há o aspeto dinâmico e narrativo do tempo, que também interferem na representação do imaginarium diegético.

Em qualquer das quatro situações mentais sonho, pensamento, lembrança ou alucinação - é comum a falta de um fluxo lógico e constante das imagens e sons, assim como a presença de imagens em movimento. Ou seja, as primeiras imagens se transformam em outras, e outras, ao longo de um sonho, de um pensamento, de uma lembrança ou de uma alucinação, assim como, a impressão da passagem de tempo também não é regular, nem respeita um fluxo cronológico.

A dilatação do tempo (mais lento, irregular e inconstante) tal como a sua condensação (com elipses e acelerações), são frequentemente utilizadas na representação do imaginarium diegético. Isso ocorre porque o homem representa o mundo como este the parece. Se nesses estados mentais o fluxo das imagens se apresenta dessa forma, é uma consequência que o homem as "copie" no sentido de reproduzi-las, para representar e fazer perceber esses estados - outro motivo da relevância do sentido comum. A forma como o homem entende e está acostumado a ver suas próprias imagens internas (mentais), é o referencial padrão.

A alteração temporal, ao se representar momentos do imaginarium diegético, tanto em animação quanto em live-action - em termos de velocidade ou de linearidade -, cria também uma diferenciação de ritmo com os outros momentos da narrativa. Como acontece em Frida (2002), com a aceleração dos movimentos feitos em Stop motion, ao representar o sonho da personagem durante o coma; e em The Beach (2000), que apresenta um ritmo irregular, com imagens psicadelicamente coloridas ao representar a personagem Richard (Leonardo Di Caprio) drogado.
Em termos narrativos (Genette 1972), se identifica o nível mental da personagem como meta-diegético, e o o nível da ação em que Frida dorme, como sendo o intradiegético. Tal facto auxilia a identificação de que este é um momento diverso da narrativa principal, que é um "estado" da personagem, que mostra a sua subjetividade. Morin $(1956,66)$ considera tais alterações como metamorfoses do tempo: "Le temps du cinéma n'est pas seulement compressible et dilatable. Il est réversible".

Porém, a metamorfose das imagens, quando uma se transforma em outra, seja por ação da transformação ou por substituição direta, é inclusive, um artifício importante tanto para a Animação quanto para o Cinema Live-action. George Sadoul $(1963,28)$ e Morin identificam os efeitos de trucagem de Méliès, como sendo metamorfoses: "[...], tous les trucs prestidigitateurs de Méliès s'enracinent en techniques clé de I 'art du film, [...]" (Morin 1956, 59). Ao seja, todo efeito de transformar algo em outra coisa, é considerado uma metamorfose.

Para a Animação, a metamorfose é uma das bases que a fundamentam, pois na realidade das ações do animador e seu resultado, todo e qualquer desenho animado, é a metamorfose da forma do seu desenho ao longo do tempo. $E$ em animação a forma se transforma realmente, sendo possível visionar essa alteração e não simplesmente a substituição direta de uma coisa por outra. Em animação vê-se uma flor aberta murchar completamente. Quando tal situação ocorre em uma produção live-action, de facto este é um efeito animado que é agregado à imagem filmada através da montagem ou efeito digital.

A metamorfose de uma imagem é uma transformação que se processa e acontece através da passagem do tempo. E o tempo é um elemento fundamental na perceção, tanto da imagem real quanto da animada, uma vez que ele apresenta uma linearidade "dentro da realidade", mas o que não ocorre necessariamente com o pensamento ou com a memória.

Portanto, identifica-se uma semelhança maior entre o comportamento das imagens mentais com a Animação e o Cinema, pois seus filmes também apresentam o tempo de forma fragmentada, analéptica e não necessariamente cronológica - como também destaca Morin (1956, 84-85).

\section{A Representação do Imaginarium Diegético na Animação e no Cinema Live-action}

Como é possível constatar, com o objetivo de criar semelhança com as imagens mentais humanas, são utilizados artifícios diversos, nas produções filmadas e animadas ao apresentar cenas do imaginarium diegético. Através desses procedimentos, é possível criar um hiato entre as imagens do nível das ações da diegese (intradiegéticas), em relações às do imaginarium das personagens (meta-diegéticas). $\mathrm{E}$ ao longo da História do Cinema, criou-se uma codificação ${ }^{15}$ para demarcar tais momentos, que é compreendida pelo público. Citando três exemplos de filmes de Animação e de Live-action: 
- em Fantasmagorie (1909): os pensamentos de um ébrio são representados através de balões onde os elementos se transformam;

- em Alice in Wonderland (1951): Alice acorda de seu sonho com cenas em fusão, efeito de dissolução das imagens;

- em 9 (2009): as lembranças de Nove são representadas por imagens também digitais, mas com efeito de filme degradado;

- em The Gold Rush (1925): Big Jim McKay (Mack Swain) vê a personagem de Chaplin, como um grande frango, através da fusão das imagens;

- em Marnie (1964): quando Marnie (Tippi Hedren) recorda o trauma de infância, as imagens aparecem matizadas de vermelho;

- em Life of Pi (2011): vários momentos de fusão de imagens, foram usados ao mostrar a história contada por Pi Patel adulto (Irrfan Khan).

Como é possível perceber, apesar de terem origens diferentes - o sonho, lembrança, pensamento e a alucinação -, a representação dessas imagens em geral são historicamente semelhantes.

Destaca-se inclusive, que André Gaudreault e François Jost (2005) observam que o Cinema criou um conjunto de códigos visuais para indicar ao público o que é ação diegética, e o que é imagem mental em um filme. Mas que desde Hiroshima mon Amour (1959), a imagem mental passou a ser uma ocularização interna (Gaudreault e Jost 2005, 130) - uma visão interna da personagem -, mas com a mesma visualidade da ação diegética principal. Ou seja, mesmo quando a transição de momentos de representação de imagens mentais se apresenta de forma abrupta (um corte seco), nítida, colorida, sem distorção do tempo de ação, o público a compreende - como acontece em Memento (2000) ou Inception (2010). Essa identificação é possível, mesmo que seja necessário um curto período de tempo de adaptação a esse sistema de construção visual (enquanto se assiste o filme), para o completo entendimento da narrativa.

Portanto, as representações da passagem do imaginarium diegético para o "consciente" da personagem, em animação e pelo Cinema Live-action, além de criar imagens semelhantes às imagens mentais, e de fazerem uso de códigos específicos, também se utilizam, por consequência, do conhecimento prévio e da memória imagética do público para compreender esses estados.

Diante do exposto até o momento, apresenta-se as tabelas 1 e 2 com uma proposta de sistematização das comparações mencionadas: as quatro formas de imaginarium diegético representados pela Animação e pelo Cinema Live-action e as caraterísticas audiovisuais das cenas e das transições.

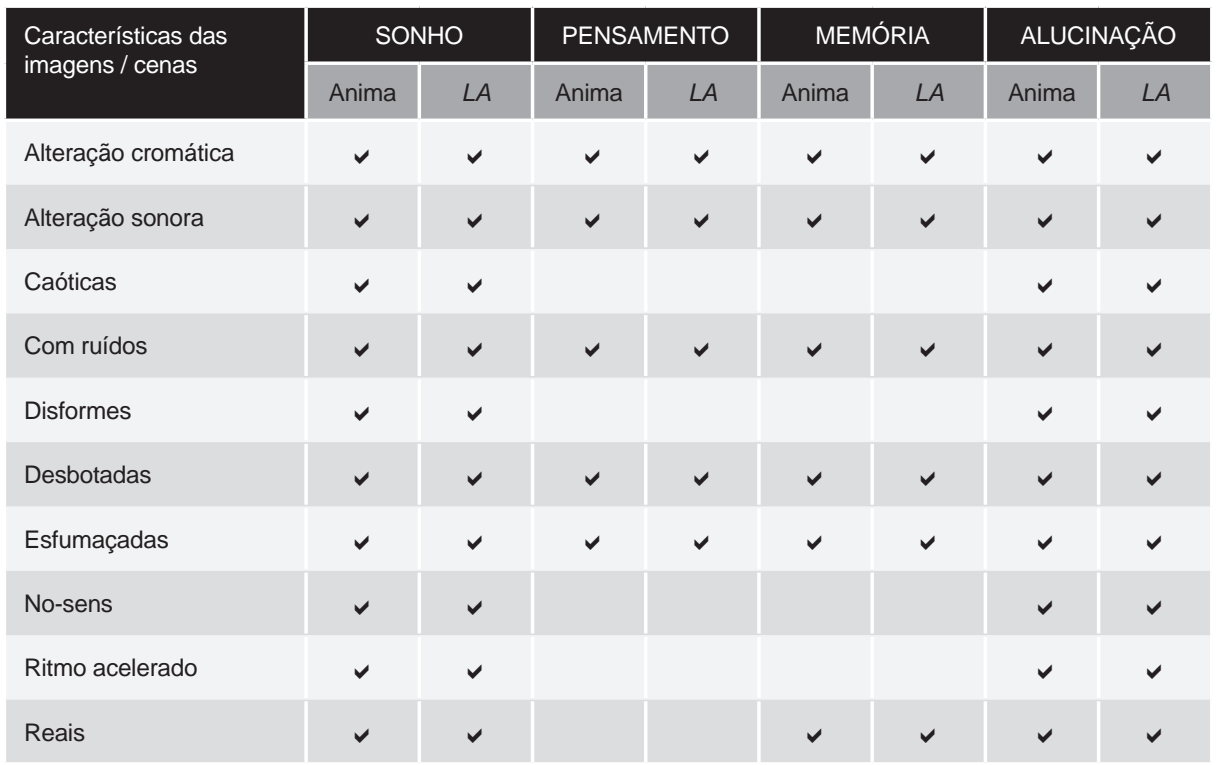

Tabela 1 - Características das Sequências do Imaginarium Diegético Presentes na Animação e no Cinema Live-action. 


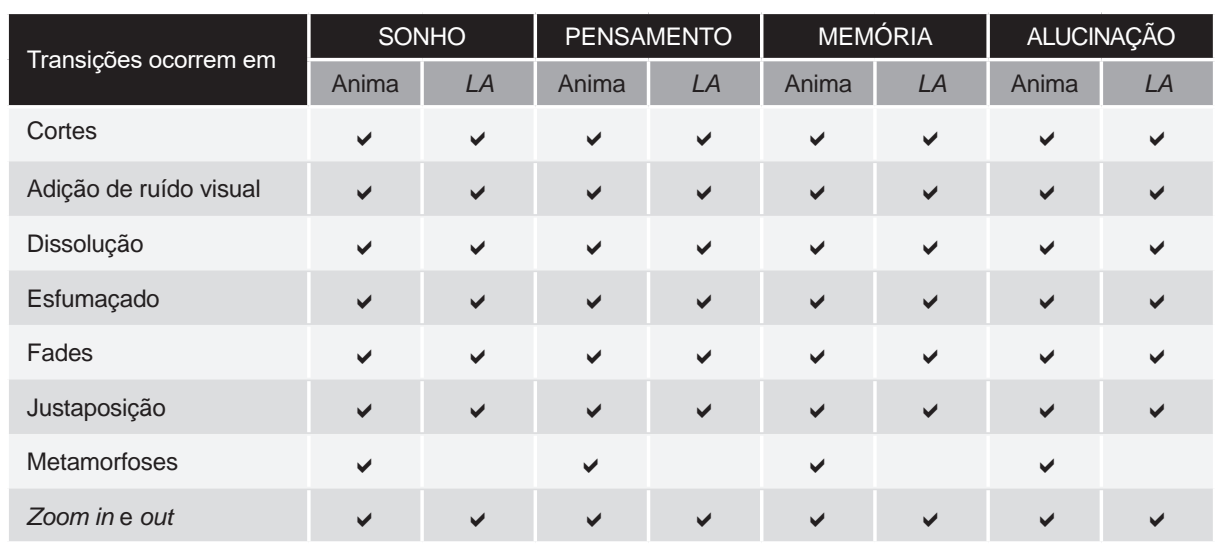

Tabela 2 - Transições (in e out) das Sequências do Imaginarium Diegético Presentes na Animação e no Cinema Live-action.

\section{O Imaginarium Diegético e o Seu Entendimento, na História e na Narrativa}

Como as sequências do imaginarium diegético são momentos da narrativa apresentados no nível metadiegético (no interior da narrativa principal), esses momentos podem apresentar, funcionar ou significar mensagens diversas, tanto para a história como para a narrativa ${ }^{16}$ de forma denotativa - informação objetiva ou conotativa - informação simbólica (Barthes 2007). Tais informações são apreendidas pelo público em um conjunto de processos que auxiliam no entendimento dessas sequências específicas, assim como do filme como um todo.

\section{Funções do Imaginarium Diegético nas Histórias e Narrativas}

Em termos da história, as sequências de imaginarium diegético podem mostrar ao público eventos do passado da personagem (flashbacks), assim como seus medos, emoções conscientes e inconscientes. Estes momentos podem ser avisos, premonições, anunciando factos futuros (forwards), prevenindo a personagem e/ou informando o espetador. Ainda podem mostrar as intenções e objetivos, o que a personagem pretende fazer, tornando visível o seu pensamento. Portanto, pode-se resumir que as sequências do imaginarium diegético da personagem têm a função de revelar, mostrar, explicar, justificar algo escondido ou desconhecido, da personagem ou na história, até aquele momento.

Em termos narrativos, as sequências do imaginarium diegético podem gerar uma pausa de uma determinada narração, podem criar expetativa e suspense, podem determinar um ritmo à narrativa (em parte ou no todo), ou ainda ser uma intriga de predestinação (Aumont 1983 $)^{17}$ - um momento em que se adianta o desenrolar de algum evento futuro da história. Ou seja, sob o ponto de vista da narrativa, as sequências do imaginarium diegético, têm a função de criar, dar ritmo, dinamismo e estimular a atenção do público na trama da história.

\section{Processo de Apreensão do Imaginarium Diegético}

O estudo aprofundado do processo de entendimento e de perceção da mente humana vai para além do espaço deste artigo. Porém, é possível um maior entendimento, de como se processa a apreensão da imagem fílmica, através do trabalho de Martin Lefebvre (1997), que apresenta o ato de spectature:

C'est une activité, un acte, à travers quoi un individu qui assiste à la présentation d'un film [...] met à jour des informations filmiques, les organise, les assimile et les intègre à l'ensemble des savoirs, des imaginaires, des systèmes de signes qui le définissent à la fois comme individu et comme membre d'un groupe social, culturel (Lefebvre 1997, p. 25).

$\mathrm{O}$ ato de spectature explica de que forma uma cena ou sequência fílmica impressiona quem a assiste. Através da adaptação de termos utilizados por Gilles Thérien ${ }^{18}$ (1944- ), Lefebvre observa que o mesmo processo se aplica à imagem fílmica (Liveaction). Este é um processo interno e particular para cada espetador, e passa-se durante o tempo de visionamento de um filme, animação, ou ao ler-se um livro. Os dois processos (ver e ler) dependem do olhar e do "conhecimento percetivo": "A percepção significante aparece mesmo quando a tarefa não o impõe" (Jimenez 2002, 21). Por esse motivo, também serve aos objetivos deste estudo para explicar o processo de apreensão das sequências do imaginarium diegético.

Lefebvre explica que assistir a um filme não é um processo único $\mathrm{e}$ independente, mas múltiplo e concomitante, através dos processos percetivo, cognitivo, argumentativo, afetivo e simbólico (Lefebvre 1997, 29). Estes sempre ocorrem em função das experiências internas de cada espetador, assim como das informações fornecidas pelo filme - tanto em termos audiovisuais, quanto narrativos. Esses cinco processos ocorrem de forma simultânea e automática, uma vez que o espetador se predisponha a assistir a 
um filme ou ler um livro. Como processos internos e individuais, não são identificados conscientemente por cada espetador, que simplesmente procura "entender" o que assiste no ecrã, depreendendo conclusões sem consciência da complexidade desse processo.

O processo percetivo compreende 0 reconhecimento do que o espetador visiona: cores, formas, movimentos, etc. Através dele é possível concluir e perceber as ações e momentos da história. Se é um sonho, uma lembrança, um pensamento ou uma alucinação da personagem - devido a certos códigos já mencionados -, assim como os sons e diálogos apresentados.

O processo cognitivo diz respeito à compreensão sobre o significado do que se assiste. Este permite o reagrupamento de informações fornecidas pelo filme (independente de ordem e tempo), que resultam em uma conclusão e entendimento do todo. Por exemplo, em Life of Pi (2012) se entende que a história contada por Pi Patel era uma "história" adaptada de factos que ele viveu: que cada animal que estava no barco salvavidas, representava (significava) um viajante do navio que afundou - há um reconhecimento da subjetividade da história e da personagem. Através deste processo - juntamente com o processo percetivo -, o espetador reconhece o momento de imaginarium diegético, que é visual e sonoramente diferente, atribuindo-lhe um peso diferente dentro da narrativa que assiste. O espetador cria conexões desses momentos com a história assistida até o momento, e com o que ainda irá assistir. Este é o processo argumentativo: o espetador organiza as conclusões sobre o que assiste, avaliando e hierarquizando informações o que lhe possibilita "entender" a história.

O processo afetivo se refere à ligação emocional que uma história pode despertar no espetador. Tem relação com a "participação" do espetador:

II déclenche chez le spectateur un processus à la fois perceptif et affectif de "participation » (on ne s'ennuie presque jamais au cinéma), il rencontre d'emblée une sorte de créance - point totale, évidemment, mais plus forte qu'ailleurs, parfois très vive dans l'absolu [...] (Metz 1994, p. 14).

A narrativa e os estímulos visuais da produção reforçam este processo, e despertam as referências emocionais do espetador. Dessa forma, como na sequência em stop motion do filme Frida (2002), que fornece ao espetador uma informação emocional da tragédia e da dor da personagem. Os médicos são bonecos-esqueletos e a coluna vertebral da personagem é um objeto manuseável.

O processo simbólico, como descreve Lefbvre,

rend compte de fait que l'acte de spectature n'est pas un acte isolé et clos qu'à travers lui un film ou un fragment filmique es susceptible de trouver un sens plus vaste en s'intégrant à la vie symbolique ou imaginaire du spectateur et d'un culture" $(1990,34)$.

Este é o processo que, no exemplo anterior, amplia a carga dramática da cirurgia de Frida. O esqueleto humano, assim como o crânio, são representações da morte (lembrando que Frida era mexicana), do tempo perene do homem sobre a terra (Gibson 2008, 59, 151). A imagem dos médicos como esqueletos, fornece ao espetador uma informação simbólica trágica sobre o momento da vida da personagem. O processo simbólico é o grande responsável, segundo Lefbvre $(1990,35)$ por criar uma memória imagética fílmica como a personagem Gilda (Rita Hayword) tirando as luvas no filme homónimo de 1946, ou Luke Skywalker em duelo de sabres de luz contra o pai, Darth Vader, em Star Wars: The Empire Strikes Back (1980). Estes exemplos são imagens gravadas nas memórias de milhões de pessoas, onde cada espetador guarda em si uma "mémoire filmique", "un musée imaginaire du cinema", segundo Lefbvre $(1997,35)$.

\section{Conclusão}

Enquanto objeto artístico, um filme (em Animação ou em Live-action) é o resultado da criatividade individual ou coletiva, sendo um representante de uma determinada época e sociedade da qual ele é originário. Como observa Michel Maffesoli (1944- ), o imaginário individual

corresponde ao imaginário de um grupo no qual se encontra inserido. O imaginário é o estado de espírito de um grupo, de um país, de um Estado Nação, de uma comunidade, etc. O imaginário estabelece vínculo (2001, p. 76).

Como produto de uma sociedade, uma animação ou filme live-action também é reflexo de sua cultura e de seu imaginário coletivo. Suas personagens, como reflexo dessas sociedades e elementos ativos de cada diegese, também sonham, têm memória, criando pensamentos e alucinações, de acordo com as caraterísticas culturais de suas origens.

É possível também constatar outro vínculo, em relação à cultura cinematográfica. Esta é composta tanto pelas produções fílmicas (seus produtores e profissionais), como também pelo público, que as assiste. Portanto, se estabeleceu uma forma relativamente semelhante de abordar assuntos, desenvolver narrativas, mas também de representar histórias, ações e personagens e que são assimiladas e compreendidas pela audiência. Por consequência, as representações do imaginarium diegético das personagens também se alinham com determinados "modelos" de representação, e que foram desenvolvidos ao longo do tempo através de produções live-action e animadas (como também um museu imaginário cinematográfico individual, como observa Lefbvre). 


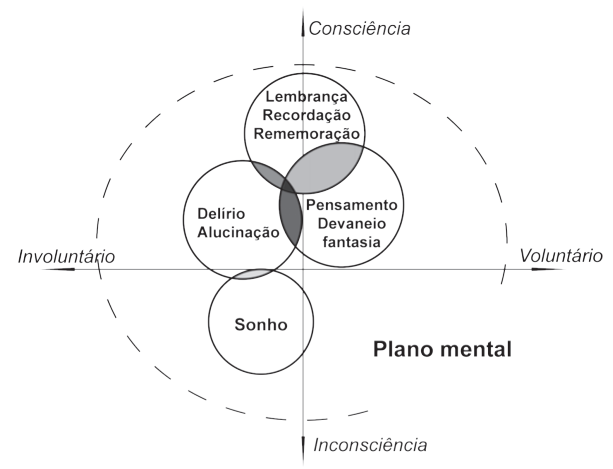

Confluência: lembrança e pensamento
Confluência: lembrança e delírio
Confluência: fantasia e alucinação
Confluência: recordação, devaneio e alucinação
Confluência: sonho e delírio

Figura 1 - Esquema da Relação de Confluência entre

Pensamento, Devaneio, Fantasia / Lembrança, Rememoração, Recordação / Delírio, Alucinação / Sonho.

Ademais, tendo em vista a transparência do Cinema (Bazin1994; Xavier 2005), o que se visiona parece ou é assumido como "existente", dentro de sua lógica própria (sua diegese), mesmo quando são pura fantasia, como na trilogia The Lord of the Rings.

Ao se apresentar imagens de sonho, estas também agregam mais "vida" à personagem - fortalecendo a sua empatia com o público pois, ela "também sonha". É pertinente lembrar também as afirmações filosóficas que reforçam esta "conclusão inconsciente" (podese dizer assim) do público quanto à "existência" da personagem: "Penso, logo existo" (René Descartes, 1596-1650) (Fortino 2013, 118) e a frase latina, "esse est percipi" (ser é ser percebido), que desenvolvida por George Berkeley (1685-1753), talvez tenha melhor tradução como, "ser é perceber ou ser percebido" (Fortino 2013, 139).

Quando uma obra cinematográfica (Live-action ou Animação) apresenta elementos intencionalmente ligados ou representativos aos sonhos, às lembranças ou às alucinações/ delírios, tal facto parece representar nela mesma, uma meta-ação pois é o surreal do surreal. É uma representação do imaginarium diegético, uma imagem mental de uma personagem que, por si só já é resultado de uma criação "duplamente" imaginada.

Nestes casos, em geral, a imagem projetada é composta de figuras e transformações que tentam aproximá-la do que se identifica visualmente, como sendo a imagem de uma "lembrança" ou de um "sonho" - próximo dos registos na memória humana. Imagens em flashes, com pouca nitidez, esfumaçadas e às vezes, com efeitos cromáticos, de envelhecimento ou em fusão, têm utilização corrente, sendo artifícios das produções de live-action e de animação. Ou seja, há toda uma simbologia visual nessa representação, que foi desenvolvida e assimilada ao longo do tempo, como uma convenção.
Apesar de terem origens diegéticas diferentes, a representação do imaginarium diegético em uma produção para o Cinema, são historicamente semelhantes. Utilizam raccords e efeitos semelhantes, assim como as lembranças, sonhos, pensamentos e alucinações, enquanto imagens mentais, se assemelham. Estas não apresentam diferença de natureza de corpo entre si, pois são pouco definidas, tendem à abstração e são manipuláveis. Assim, essas representações também se assemelham às formas similares de se "figurar", através de imagens visíveis, o que divaga, sonha, lembra ou alucina a personagem. Dessa forma, interpretando que a própria fronteira entre esses estados não é rigidamente definida principalmente em uma narrativa - se apresenta a proposta de esquema, de confluências possíveis desses estados, que muitas vezes se confundem (Fig. 1).

O estudo de Sifianos sobre a característica de abstração da imagem mental, corrobora para se compreender o facto de muitas produções (live-action ou 3D) utilizarem, em sua grande maioria, a técnica do desenho animado para representar imagens mentais das personagens. Ao trabalhar com elementos do mundo real, o Stop motion (quando trabalha com bonecos e objetos) fica no meio termo - imagem live-action / imagem animada - sendo útil na relação físico-metafórica na construção de uma imagem conotativa para a narrativa. Mas observa-se também a dificuldade e o maior custo, em se produzir um stop motion com bonecos, em comparação a um desenho animado. Porém, a questão da materialidade da técnica tende a carregar um certo grau de visceralidade na imagem, mais ligada ao grotesco, ao terror - tão bem desenvolvido por Jan Švankmajer e os Quay Brothers. Enquanto o desenho em si, carrega algo de incontrolável, de imprevisível na sinuosidade de suas linhas. Esta técnica, como o stop motion com bonecos, também cria inevitavelmente conexão com as memórias infantis do público, com seus desenhos e brincadeiras.

Outra consequência da representação do imaginarium diegético, é uma certa imersão maior na história, propiciada sobretudo pela própria diegese. Esta oferece à audiência um aprofundamento na história e na "vida" desta personagem, que deixa de ser "plana" e passa a ter uma profundidade. O facto deste momento ser representado em imagem animada, visualmente diferente da imagem fotorealista, cria uma outra dimensão na narrativa. Tal facto provoca uma rutura visual, que impõe à audiência um outro entendimento do que se passa, que expande a sua perceção, até então acomodada com a imagem objetiva e foto-realista do live-action.

\section{Notas finais}

1 Como observa Aumont (1983, 100), a verosimilhança "peut d'abord se définir dans sa relation à l'opinion commune et aux bonnes mœurs : le système du vraisemblable se dessine toujours en fonction de la bienséance".

2 "[...] à la richesse perceptive des matériaux filmiques, de l'image et du son. En ce qui concerne l'image cinématographique, cette « richesse » est due à la fois à la très grande définition 
de l'image photographique [...] qui présente au spectateur des effigies d'objets avec un luxe de détails, et à la restitution du mouvement qui donne à ces effigies une épaisseur, un volume qu'elles n'ont pas dans la photo fixe [...]". (Aumont 1983, 104).

${ }^{3}$ Em Biographia Literaria (1817), o poeta Samuel Taylor Coleridge (1772-1834), apresenta a expressão pela primeira vez.

${ }_{4}^{4}$ Como em Les Transfigurations (1909) e Les Joyeux Microbes (1909).

${ }^{5}$ Definição de Jacques Aumont: “[...] a representação é um processo pelo qual institui-se um representante que, em certo contexto limitado, tomará o lugar do que representa" (2001, 103), e também a considera como sendo, "o que permite ao espectador ver 'por delegação' uma realidade ausente, que the é oferecida sob a forma de um substituto", onde a representação pode "provocar" uma ilusão $(2001,105)$.

6 "[...] trata-se de uma série de cenas, umas vezes inteiramente comuns, outras vezes estranhas e desarticuladas, [...]. Enquanto se desenrola, a representação do sonho é, em regra, experimentada como real. [...]" (Gleitman, Fridlund e Reisberg 2014, 6).

${ }^{7}$ No sentido de pensar, imaginar, fantasiar: "um estado de fantasia vago e não dirigido" ou ainda "como um conjunto de atividades internas que são utilizadas sempre que tentamos resolver um problema [...]" (Gleitman, Fridlund e Reisberg 2014, 399).

${ }^{8}$ Ou memória, "é a maneira como fazemos o registro dos acontecimentos das nossas vidas, e também das informações e competências que respigamos desses acontecimentos" (Gleitman, Fridlund e Reisberg 2014, 343). Pode ter o sentido de um grande arquivo de informações pessoais vividas, ou de registo desse arquivo.

9 Ou alucinações "consistem em experiências que são percebidas na ausência de estimulação sensorial real" (Gleitman et al. 2014, 1048). Muitas vezes "se devem a uma incapacidade para distinguir entre experiências que se originam no interior e experiências exteriores, ou seja, entre memórias e fantasias e perceções exteriores" (idem). A alucinação pode ser uma consequência de uma psicopatologia (1029-1100).

10 Não há conexão desta expressão, com o conceito de "Museu Imaginário" (1965), de André Malraux (1901-1976).

${ }^{11}$ Em uma produção live-action, também há uma elaboração prévia da imagem a ser captada. Mas esta imagem será sempre uma imagem fotográfica, de natureza realista.

12 Apesar do senso comum ser rechaçado pela ciência (Santos 1989), principalmente a que trabalha com dados quantitativos, a sua utilização é necessária. A cognição e a relação do homem com seus pensamentos e as imagens audiovisuais, de forma quotidiana, é um elemento importante a ser considerado. O senso comum surge com a burguesia emergente do século XVIII (Santos 1989, 39). Assim, carrega o estigma de preconceito e menos valia. Mas é "prático e pragmático; reproduz-se colado às trajectórias [sic] e às experiências de vida de um dado grupo social e nessa correspondência se afirma de confiança e dá segurança. [...]." (Santos 1989, 89).

${ }^{13}$ É o processo da memória: estado pré-atento/consciente (duração 250ms), memória de trabalho (MDT) (duração, 30s.) e a memória de longo tempo (MLT) (Jullier 2002, 28-29).

14 "[...] dizemos que um sistema conotado é um sistema cujo plano de expressão é ele próprio constituído por um sistema de significação" (Barthes 2007, 88).

15 Considerando que código é "um sistema de correspondências, seja convencional, seja natural, entre um signo e uma significação" (Aumont e Marie 2006, 55).

${ }^{16}$ A narrativa conta a história, podendo ser verbal, literária, musical, visual ou audiovisual. A história é o que se conta.

${ }^{17}$ Expressão usada por Marc Vernet (in Aumont 1983, 86), mas que foi primeiramente mencionada por Todorov $(1978,35)$ e citada por Gennete $(1972,105)$.

${ }^{18} \mathrm{Em}$ seu texto, Pour une sémiotique de la lecture (Protée, vol. 18, n. 2, 1990).

\section{Bibliografia}

Arnheim, Rudolf. 1971. Visual Thinking. Berkeley: University of California Press.

Arnheim, Rudolf. 2004. Art and Visual Perception: A psychology of the creative eye. The New Version. Berkeley: University of California Press.

Aumont, Jacques, org. 1983. L'Esthétique du Film. Paris : Éditions Fernand Nathan.

Aumont, Jacques. 2001. A Imagem (Traduzido do francês por Estela dos Santos Abreu e Carlos Cesar Santoro). (5a. ed.). São Paulo: Papirus Editora.

Aumont, Jacques, Marie, Michel. 2006. Dicionário Teórico e Crítico do Cinema (Traduzido do francês por Eloisa Araújo Ribeiro) (2a. Ed.). São Paulo: Papirus Editora. Aumont, Jacques. 2011. L'Image (3a. Ed.). Paris : Armand Colin.

Barthes, Roland. 1980. La Chambre Claire : Note sur la photographie. Paris : Cahiers Du Cinéma, Gallimard Seuil.

Barthes, Roland. 2007. Elementos de Semiologia (Traduzido do francês por Maria Margarida Marahona). Lisboa: Edições 70.

Bazin, André. 1994. Qu'est-ce que le Cinéma? (12a. Ed.). Paris: Les Éditions Du Cerf.

Bergson, Henri. 1999. Matéria e Memória: Ensaio sobre a relação do corpo com o espírito (2a . Ed.) (Traduzido do francês por Paulo Neves). São Paulo: Livraria Martins Fontes Editora Ltda.

Bergson, Henri. 2008. Le mécanisme Cinématographique de la Pensée [1907]. In Banda, Daniel; Moure, José. Le Cinéma: Naissance d'un art 1895-1920 (pp. 131-134). Paris: Èditions Flammarion.

Baecque, Antoine de, Chevallier, Philippe. 2016. Dictionnaire de la Pensée du Cinéma (2a. Ed.). Paris: Presses Universitaires de France.

Cholodenko, Alan. 1991. The Illusion of Life: Essays on animation. Sidney: Power Publications.

Cholodenko, Alan. 2007. The Illusion of Life II: More essays on animation. Sidney: Power Publications.

Durand, Gilbert. 1995. A Imaginação Simbólica (Traduzido do francês por C. A. Brito). Lisboa: Edições 70. Fortino, Carla, ed. 2013. O Livro da Filosofia (Traduzido do inglês por Douglas Kim). São Paulo: Editora Globo.

Freud, Sigmund. 2012. A Interpretação dos Sonhos (Traduzido do alemão por Renato Zwick). Volume 1. Porto Alegre: L\&PM.

Genette, Gérard. 1972. Figures III. Paris: Editions du Seuil.

Gleitman, Henry, Fridlund, Alan e Reisberg, Daniel. 2014. Psicologia (10 ${ }^{\mathrm{a}}$. Ed.) (Traduzido do inglês por Danilo Silva). Lisboa: Fundação Calouste Gulbenkian.

Harryhausen, R.; Dalton, T. 2008. A Century of Stop motion Animation: From Méliès to Aardman. New York: Watson-Guptill Publications.

Jimenez, Manuel. 2002. A Psicologia da Percepção. Traduzido do francês por A. Viegas. Col. Biblioteca Básica de Ciência e Cultura. Lisboa: Instituto Piaget.

Jullier, Laurent. 2002. Cinéma et Cognition. Paris: L'Harmattan.

Lefebvre, Martin. 1997. Psycho: De la figure au musée imaginaire - Théorie et pratique de l'acte de spectature. Montreal/ Paris: L'Harmattan.

Maffesoli, Michel. 2001. O Imaginário é uma Realidade. Revista Famecos. 15, Ago. 2001. 74-82. http:// revistaseletronicas.pucrs.br/ojs/index.php/revistafamecos/ article/viewFile/3123/2395. Acedido em 02 de junho de 2016. 
Méliès, Georges. 2008. Les Vue Cinématographiques [1907]. In Banda, Daniel; Moure, José. Le Cinéma: Naissance d'un art 1895-1920 (pp. 95-107). Paris: Éditions Flammarion.

Metz, Christian. 1975a. Le signifiant imaginaire. Communications, 23, 1975. Psychanalyse et cinéma. (355).http://www.persee.fr/doc/comm_0588-8018_1975_ num_23_1_1347. Acedido em 06 de abril de 2016.

Metz, Christian. 1975b. Le film de fiction et son spectateur. Communications, 23, 1975. Psychanalyse et cinéma (108-135). http://www.persee.fr/doc/comm 05888018_1975_num_23_1_1354. Acedido em 06 de abril de 2016.

Metz, Christian. 1994. Essais Sur la Signification Du Cinéma (Tomo 1). Paris: Éditions Klincksieck.

Morin, Edgar. 1956. Le Cinéma ou L'homme Imaginaire: Essai d'anthropologie sociologique. Paris: Arguments Les Editions De Minuit.

Pavis, Patrice. 1996. A Análise dos Espetáculos (Traduzido do francês por Sérgio Sálvia Coelho). São Paulo: Editora Perspectiva, 1996.

Sadoul, George. 1963. A História do Cinema Mundial das Origens aos Nossos Dias. Vol. I. São Paulo: Martins Fontes Editora.

Santos, Boaventura de Sousa. 1989. Introdução a uma Ciência Pós-Moderna (6 ${ }^{a}$ Ed.). Porto: Afrontamento.

Sifianos, Georges. 2012. Esthétique du Cinéma d'Animation. Paris: Editions Cerf-Corlet.

Todorov, Tzvetan. (1978). Poétique de la Prose. Paris: Éditions Seuil. ISBN: 2-02-005693-3.

Wells, Paul. 2002. Animation: Genre and authorship. London: Wallflower Press.

Xavier, Ismael. 2005. O Discurso Cinematográfico: A opacidade e a transparência (3a. Ed.). São Paulo: Editora Paz e Terra.

\section{Filmografia}

9. 2009. De Shane Acker. USA: Black Focus Features et al. DVD.

Alice in Wonderland. 1951. De Clyde Geronimi, Wilfred Jackson, Hamilton Luske. USA: Walt Disney Productions. Filme.

Frida. 2002. De Julie Taymor. USA, Canada, Mexico: Handprint Entertainment et al. DVD.

Gilda. 1946. De Charles Vidor. USA: Columbia Pictures Corporation.

Hiroshima mon Amour. 1959. De Alain Resnais. France, Japon: Argos Films et al. DVD.

Inception. 2010. De Christopher Nolan. USA, UK:

Warner Bros., Legendary Pictures, Syncopy. DVD.

Je Me Souviens Donc Je Me Trompe. 2016. De Raphaël Hitier. France: ARTE France, Scientifilms, CNRS Images. Filme televisionado (2017, setembro 21).

Les Joyeux Microbes. 2009 [1909]. De Émile Cohl.

France: Gaumont Vidéo. DVD.

Les Transfigurations. 2009 [1909]. De Émile Cohl.

France: Gaumont Vidéo. DVD.

Life of Pi. 2012. De Ang Lee. USA, Taiwan, UK: Fox 2000 Pictures et al. DVD

Marnie. 1964. De Alfred Hitchcock. USA: Universal

Pictures, Alfred J. Hitchcock Productions, Geoffrey Stanley.

DVD.

Memento. 2000. De Christopher Nolan. USA: Newmarket Capital Group et al. DVD.
Star Wars: The empire strikes back. 1980. De Irvin Kershner. USA: Lucasfilm.

The Beach. 2000. De Danny Boyle. UK, USA: Figment Films. DVD.

The Gold Rush. 1925. De Charlie Chaplin. USA: Charles Chaplin Productions. DVD.

Toy Story 3. 2010. De Lee Unkrich. USA: Walt Disney Pictures, Pixar Animation Studios. Filme. DVD. 